\title{
BMJ open Facilitating and inhibiting factors for long-term involvement of patients at outcome conferences - lessons learnt from a decade of collaboration in OMERACT: a qualitative study
}

\author{
Maarten de Wit, ${ }^{1}$ Tineke Abma, ${ }^{1}$ Marije Koelewijn-Van Loon, ${ }^{2}$ Sarah Collins, ${ }^{3}$ \\ John Kirwan ${ }^{4}$
}

To cite: de Wit M, Abma T, Koelewijn-Van Loon M, et al. Facilitating and inhibiting factors for long-term involvement of patients at outcome conferenceslessons learnt from a decade of collaboration in OMERACT: a qualitative study. BMJ Open 2013;3:e003311.

doi:10.1136/bmjopen-2013003311

- Prepublication history and additional material for this paper is available online. To view these files please visit the journal online (http://dx.doi.org/10.1136/ bmjopen-2013-003311).

Received 28 May 2013 Revised 17 July 2013 Accepted 19 July 2013

For numbered affiliations see end of article.

\section{Correspondence to} Maarten de Wit; mp.dewit@vumc.nl

\section{ABSTRACT}

Objective: Several studies have provided insights into the conditions for successful patient involvement in health research. We recently demonstrated that long-term engagement with people with rheumatic conditions in international outcome research led to significant changes in the research agenda in the field of rheumatology. This article explores facilitating and inhibiting factors for long-term involvement of patients as collaborative partners at five Outcome Measures in Rheumatology (OMERACT) conferences.

Design: Responsive evaluation, starting with a thematic document analysis of conference proceedings and the grey literature, followed by 38 qualitative interviews. Interview transcripts were subjected to inductive content analysis.

Setting: 5 international OMERACT conferences between 2002 and 2012.

Participants: Patient delegates $(n=16)$ and professional delegates representing researchers $(n=14)$, pharmaceutical industry and regulators $(n=2)$.

Results: Combined review of the document analysis and interview data revealed five main facilitators and three main barriers. Patient engagement as full participants at OMERACT conferences was enhanced by: strong leadership commitment and the presence of change agents, a clear selection procedure, an inclusive consensus-based conference design, individualised and self-organised support, an interactive and encouraging moderation style during discussion groups. Barriers were related to the intensity of the conference programme, scepticism among researchers and doubts about the representativeness of the patient group.

Conclusions: This study concludes that developing a sustainable structure for funding, selection and support of patient delegates, as well as adjusting conference design and moderation style, contributes not only towards facilitating direct dialogue between all stakeholders but also towards enhancing mutual understanding and the successful incorporation of the patient perspective in an outcome conference such as OMERACT.

\section{ARTICLE SUMMARY}

Article focus

- The biannual conference on Outcome Measures in Rheumatology (OMERACT) has extensive experience with the structural involvement of patients as collaborating partners in outcome research.

- Through a systematic document analysis and 38 qualitative interviews with all stakeholders, we explore the facilitators for and barriers to longterm participation of patients in outcome research.

\section{Key messages}

- Making patient participation an integral part of the conference vision, structure and programme enables the effective and efficient inclusion of the patient perspective.

- Suitable introduction and personalised training and support for patients are important conditions for successful engagement with patients.

- The role of moderators in small group discussions is pivotal for enabling patients to contribute to research and to foster the mutual learning processes of all participants.

Strengths and limitations of this study

- OMERACT is a unique opportunity to evaluate the requirements for the long-term involvement of patients as conference partners in a highly scientific environment.

- Issues of generalisability and transferability of the result findings to conferences at the national and local levels and to other disciplines are limited and additional research is required.

The past decade has seen an increase in the number of patients becoming involved in health research. The background to this is the general trend towards empowered health consumers and an acknowledgement of 
patients' entitlement to influence research that will affect their daily life. Patients aspire to more horizontal and deliberative partnerships with researchers, which has resulted in a range of different patient roles. ${ }^{1-4}$ Patients may be: committee members, reviewers of protocols or grant applications, advisors, panel members or research commissioners. Each patient role implies different tasks and different kinds of contributions, and roles can be performed at different levels of involvement. ${ }^{5}{ }^{6}$ Most case studies observe a power shift between patients and researchers. However, participative research remains to be justified since there is still little evidence as to the effectiveness of these new patient roles. ${ }^{7}$

One new role in health research is that of the patient as a conference partner. Patients in this new role do not participate as patient advocates or representatives of patient organisations. Also, they do not attend conferences for networking purposes or learning about new developments related to their condition. With a view in providing the patient perspective, patients are invited to collaborate with researchers as equal partners. This is the case with OMERACT: the Outcome Measures in Rheumatology conferences. Here patients have successfully changed the research agenda, contributed towards developing core outcome sets and helped to devise new measurement instruments. ${ }^{8}$ As far as we are aware, there is no literature that explores the tasks, contributions and challenges of patients as collaborating partners at scientific conferences. We do, however, know more about patient research partners, a role that is similar to that of patients as conference partners. The term patient research partners was coined in the context of rheumatology ${ }^{9}$ and can be defined as "persons with a relevant disease who operate as active research team members on an equal basis with professional researchers, adding the benefit of their experiential knowledge to any phase of the project'. ${ }^{10}$ Patient research partners have actively contributed towards developing research agendas for people with spinal cord injuries, ${ }^{11}$ intellectual disabilities ${ }^{12}$ and chronic kidney disease. ${ }^{13}$ Patient research partners can also be involved in developing research designs, collecting data and in the development of patient-reported outcomes. ${ }^{14}$ Patient research partners at the Department for Rheumatology at the University of Bristol have contributed to the study of fatigue. ${ }^{15}$ Internationally, patient research partners have been involved in the study of flares in rheumatoid arthritis (RA) ${ }^{16}$ and in the development of a new patient-derived quality of life measure for RA. ${ }^{17}$

There is some evidence that the active involvement of patient research partners brings with it several benefits to research, ${ }^{18} 19$ but there is little evidence or consensus about the factors that facilitate or constrain effective involvement. OMERACT is the first series of international research conferences that has successfully engaged with patients as collaborating partners over a substantial period of time. ${ }^{8}$ However, it is still not known which factors support this success, how the culture, structure and procedures have facilitated patients to contribute effectively and how previously reported barriers have been removed. The objective of the present study was to describe how OMERACT has organised structural collaboration with patients in its conferences over the past decade, and to examine which factors have supported or inhibited this process. We also analyse how this process has changed OMERACT delegates' perceptions and beliefs on patient involvement.

\section{CONTEXT: OMERACT}

OMERACT started in 1992 to achieve consensus on a core set of outcome measures for clinical trials in RA. Based on the success of the first conference, it went on to become a worldwide, data-driven working conference known for its interactive conference design and high scientific rigour. The conference brings together a wide range of professionals with an interest in the methodology of clinical trials in the field of rheumatology. The objective is to build consensus on core outcome sets and appropriate measurement instruments for clinical trials. Since 2002, OMERACT has invited patients as full conference participants based on the belief that outcomes for clinical trials need to be derived from the lived experience of arthritis' and from 'concepts which can be readily communicated to patients to help with therapeutic decision making' ${ }^{20}$ A total of 58 patients took on this role between 2002 and 2012. Of the 172 conference participants at OMERACT 10 (2010), there were 152 professionals and 20 partners. Partner characteristics are given in the online supplementary figures S1-S5.

In a separate case study, we explored the expectations and experiences of patients who were participating in OMERACT for the first time. ${ }^{21}$ They reported a number of barriers to full collaboration with professionals, such as preparation, the professionals' moderation style and the lack of individual support on site. They believed that the contributions they made to the breakouts were not significant, and that their experiential knowledge was not optimally used. They believed, nevertheless, that their involvement had been valuable and meaningful. They confirmed that they had experienced personal learning curves, and felt that they would be able to contribute more effectively at a subsequent conference.

In a previous publication in which we reported on the impact of patient participation in OMERACT, researchers confirmed that the involvement of new and experienced patients had been a success and that this had significantly influenced the conference outcomes. ${ }^{8}$ Patients had enriched the research agenda with new topics such as well-being, flares, sleep disturbances and, most illustrative of all, fatigue. A substantial amount of work on fatigue in RA has been published, ${ }^{22}{ }^{23}$ and OMERACT participants have almost unanimously confirmed that this research would not have been rigorously conducted or even identified without patients being present at the conferences. 


\section{Challenges}

In this study, we address a number of challenges that we are aware of from previous studies that have examined the role of patients as research partners. One of the most important challenges is the fact that personal experience or lay knowledge is not accepted as a valid source for scientific research. ${ }^{24}$ It is often perceived as inferior compared with professionals' evidence-based knowledge. ${ }^{25}$ This means that patients find it hard to create a basis for trust or for equal collaborative relationships. ${ }^{18} 26$ Caron-Flinterman et $a l^{27}$ studied 23 cases of active patient involvement in biomedical research and argued that the deliberate use of patients' experiential knowledge requires additional research. Recent studies have demonstrated that starting with dialogue and deliberation among patients in collaboration with patient research partners is an effective way to strengthen their voice and develop a shared knowledge base grounded in the experiential knowledge of individuals. ${ }^{18} 19$ However, further understanding of the nature and significance of lay knowledge in the context of medical research and research conferences is still necessary.

A second challenge is that some researchers are reluctant to engage with patients and believe that involving patients amounts to some kind of tokenism. ${ }^{28}$ Other researchers may have difficulty adjusting their language and communication style, which only perpetuates a significant barrier to collaboration. Elberse et $a l^{29}$ studied the effectiveness of inclusion strategies to incorporate patient perspectives in the development of a research agenda for people with congenital heart disease. This study concluded that verbal communication is an important inhibiting factor and additional inclusion strategies are needed if an effective partnership between patients and professionals is to be achieved.

A final recurring challenge is the lack of knowledge required to implement the structural involvement of patient research partners. ${ }^{6}$ Structural involvement means that the initiative to engage with patients is not incidental and is not dependent on the goodwill of one or two individuals. In contrast, it is a long-term commitment to engage with patients by making patient participation an integral part of the vision, structure and practice of the organisation. The evidence base underpinning the assessment of effective conditions for patient involvement is relatively weak, due primarily to poor documentation, analysis and reporting.

\section{METHOD}

\section{Data collection}

Data collection was based on a thematic document analysis and 38 interviews with representatives of all stakeholders involved in OMERACT. The document analysis included OMERACT conference proceedings and the grey literature such as OMERACT policy documents, correspondence, invitations, session reports and emails. The document review focused on the objectives and structure of the conference, the number of patient delegates, their selection, preparation and support, and the rheumatic conditions and countries represented. We were particularly interested in the explanation and arguments given for the way OMERACT created, changed or improved operational procedures and the way participants accepted or adjusted them.

Following the document review, the first author performed a responsive evaluation ${ }^{30}$ by conducting qualitative interviews with representatives of all stakeholders before, during and within 4 weeks following the 2010 conference. Finally, the opinions and experiences of 16 professionals and 16 patients were collected (table 1). Of the eight patient delegates who attended OMERACT for the first time, three were interviewed on three different occasions during the 5-day conference. This was carried out to obtain accurate insights into any changes that occurred in their expectations, experiences and contributions.

All interviews were recorded, transcribed by an independent secretariat and subjected to a responder check. The interviews lasted an average of $52 \mathrm{~min}$. The interview protocols differed for professionals, new patients and experienced patients. The topics covered the expected role of patient participants, their selection, preparation and support, and their experiences in discussion groups, in particular those during the workshops on remission and flares. All participants gave their informed consent prior to the interview.

\section{Interviewee selection}

Maximum variation was the aim when selecting interviewees, and the selection was made using an emergent purposive sampling approach, based on the stakeholder's background, opinion about patient involvement, gender, geographical spread and number of OMERACT conferences attended. The selection strategy took account of the limitations inherent in a 5-day international conference. Potential candidates for face-to-face interviews should be willing to dedicate some of their time for the interview during the conference. Preliminary analyses of the initial interview data conducted immediately after the conference revealed an unexpected response shift. The attitude towards patient involvement of professionals, who were initially assumed to be critical, had changed significantly. Their scepticism had made way for a more positive assessment of collaboration and its benefits. For this reason, we sought out two new interviewees who were known for their critical perspective. The views of a research fellow and a postdoc researcher were missing and subsequently added to the list of interviewees. Saturation was achieved after the additional transcripts had been analysed.

\section{Data analysis}

An inductive content analysis of all the data was performed. The entire interview transcript was first read to identify emerging themes and subthemes related to the 
Table 1 Characteristics of interviewees

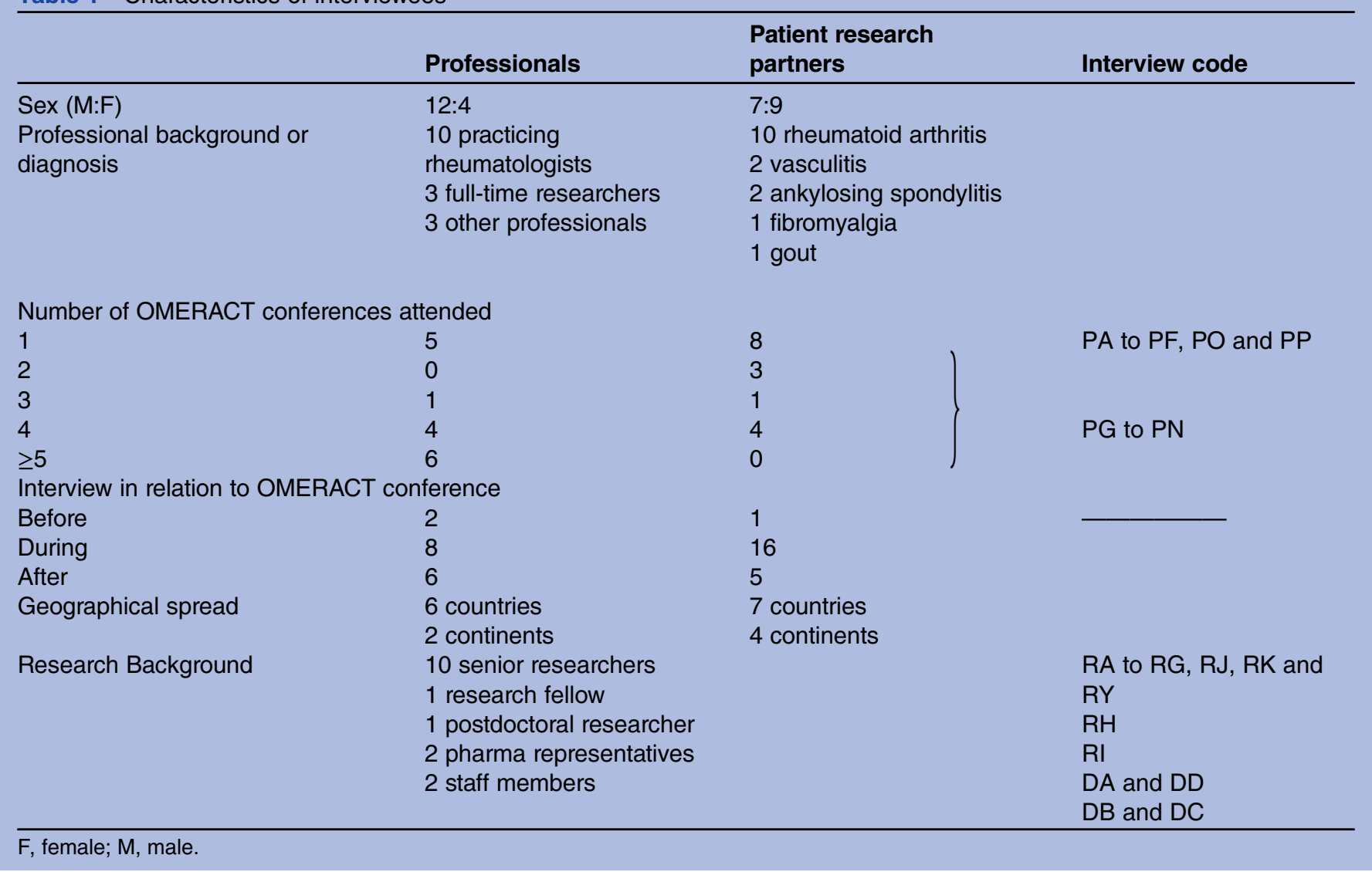

research topic of facilitators for and barriers to patient participation in OMERACT conferences. All text fragments were given a descriptive label or code relating to a specific theme or subtheme. For example: "there is still an undercurrent that questions the issue of the added value of patient input" was labelled as "(low) expectations of patients' contribution". Each interview was first analysed separately. Any new emerging theme was added to the process of labelling and analysis, and also adopted for the interviews previously analysed. This is referred to as open coding. In the subsequent axial coding step, the data from the different interviews were compared (cross case analysis) and grouped into clusters based on the main emerging (sub)themes. The descriptive labels were removed by interpretive codes that refer to the meaning of an experience. In our example, the labels were placed under the subtheme of 'doubts about the added value' and 'resistance to change'. In the final step, we concluded that both themes were strongly related to 'scepticism among researchers', which was identified as one of the three main barriers to implementing structural patient participation. An example of the audit trail of some of the text fragments can be found in online supplementary appendix 1 .

The quotations of the different interviewees were compared and example citations were identified per cluster and theme. A further understanding of the facilitating and hindering factors was obtained by comparing the themes among those participants who were satisfied about the conference as opposed to those who were more critical.

The analysis concentrated on those aspects involving how the conference was conducted, the preparation and the breakout sessions that have a direct influence on the ability of patient delegates to contribute. The documents and the interview data were analysed with a view in ascertaining what structural arrangements OMERACT made to facilitate the incorporation of patient knowledge in the conference. All team members-representing different perspectives and professional backgrounds-were involved in the data analysis and interpretation.

\section{Quality procedures}

Triangulation was carried out by synthesising interview data and results from the document analysis. In order to improve the relevance and quality of the analysis and interpretation of the data, a patient who attended OMERACT 10 for the first time (SC) joined the research team. She was actively involved in the data coding and analysis, team meetings and in drafting this article. To increase the inter-rater reliability of the coding, an external expert in qualitative research (MK-VL), who had never worked with conference partners before, participated in all phases of the study, starting with the 
transcript coding phase. All quotes in this article are presented as if made by female participants in order to preserve participant anonymity. Quotes by professionals are indicated by ' $R$ ' and those of conference partners (in short: 'partners') by 'P'.

\section{RESULTS}

During the combined review of the document analysis and the coding of the interview transcripts, the research team grouped 1563 open codes into 44 meaningful generic categories, 29 of which were descriptors of facilitators and 15 were descriptors of barriers. In a second review round, eight main categories emerged that characterised the conference elements that either supported or inhibited the contributions made by partners. The team finally defined the content of these categories and divided them into five main facilitators and three main barriers (table 2). The five facilitators included: the role of leadership, selection procedure, conference design, moderation style and support. The three barriers were the programme intensity, scepticism among researchers and representativeness of the patient group. Each main facilitator and main barrier is described below with examples from the data.

\section{Facilitators}

\section{Leadership}

Long-term commitment and support of opinion leaders are key to the success of new initiatives. The OMERACT organising committee was intrinsically motivated to foster patient engagement in the conference: "We believe their input is essential to decide on the right measurement tools." ${ }^{31}$ According to one of the members of this committee, the decision to invite patients was not taken lightly but was discussed at several planning meetings. The committee felt daunted by the question: "How to organise patient participation?" (RD). When the decision was taken, the leadership was determined to do it properly. They gave full support to the patient perspective working group leader who took on the role of a change agent and provided funds to enable patient partners to attend the conference. These costs amounted to over US\$80000 in 2012. They also acknowledged the repeated contributions made by partners: "Their dedication to the process is an example for us all" (ibid). Based on the positive experiences of two conferences attended by partners, OMERACT formulated basic principles for patient engagement in 2006: "OMERACT policy on including the patient perspective

Table 2 Facilitating and inhibiting factors for structural involvement of patients

\begin{tabular}{|c|c|}
\hline Facilitating factors & Inhibiting factors \\
\hline 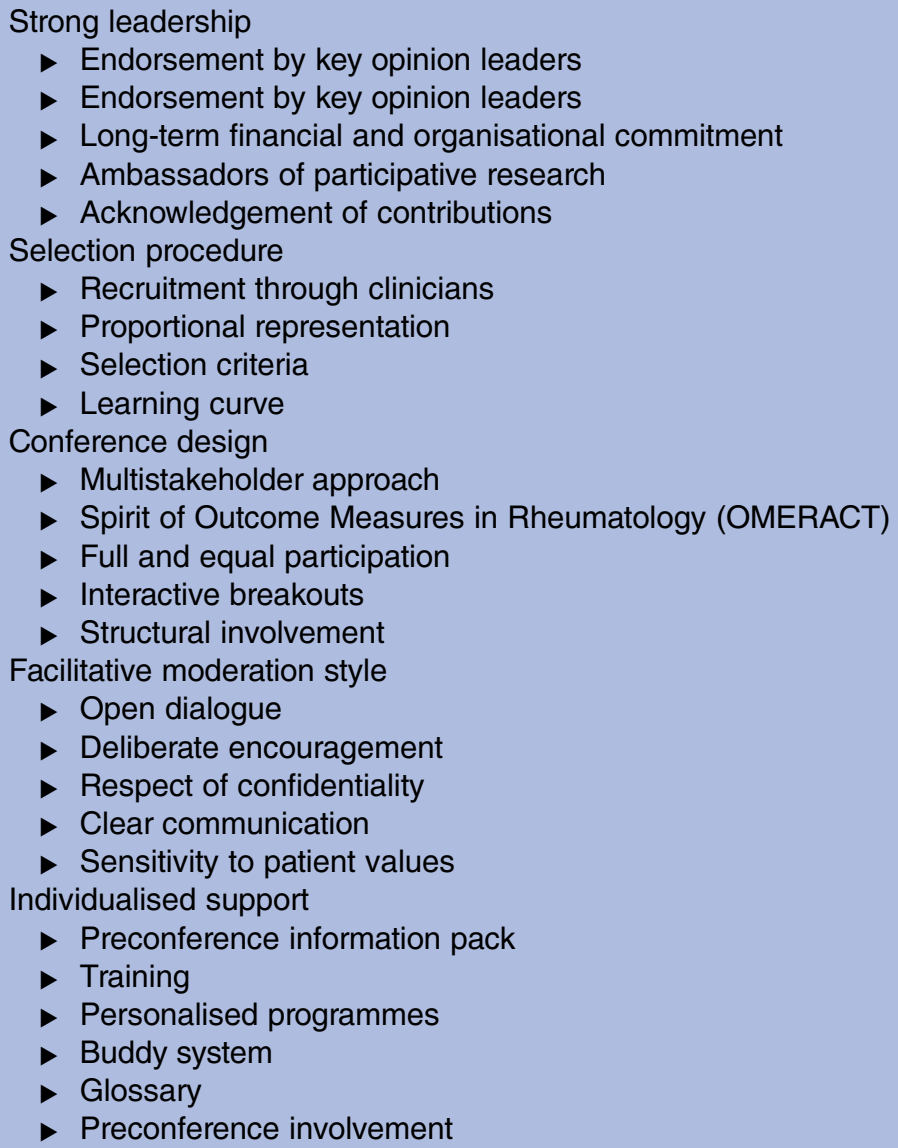 & $\begin{array}{l}\text { Intensity of the programme } \\
\text { Physically challenging } \\
\text { Intercontinental travel } \\
\text { Accessibility } \\
\text { Mentally challenging } \\
\text { Language and terminology } \\
\text { Remote themes } \\
\text { Doubts about added value } \\
\text { Risk of tokenism } \\
\text { Imperceptibility of contributions } \\
\text { Lomposition patient group } \\
\text { Lack of representativeness } \\
\text { Pseudoprofessionalism }\end{array}$ \\
\hline
\end{tabular}


in rheumatology outcomes assessment" (internal document). This document was a milestone because it made patient participation part of OMERACT's vision, embedded in a set of operational procedures. After three further conferences, the Executive Committee agreed on the principle that active patient involvement would be a prerequisite for working groups to put forward themes for the OMERACT programme. ${ }^{20}$

The leadership recognised the value of a mixed group of new and experienced partners and was committed in providing opportunities for experiments and long-term learning. They confirmed that a learning curve is a requisite for being productive.

\section{Selection}

It was clear from the outset that patient participants were not expected to represent any group or organisation. Although partners might be members of patient organisations, their role at OMERACT should be strictly personal and individual. Their contribution is valuable purely because of their personal experience: "a living knowledge of their long-term conditions" and "the unpredictable nature of their illness" (internal report, 2008). Their input is not linked at all to advocacy for resources or to attention for a particular disease. Recruitment is carried out through the clinic of participating physicians to ensure that people were invited who could make a contribution in unfamiliar circumstances' ${ }^{32}$ In practice physicians proved to be in an ideal position to identify eligible patients simply because they were familiar with the patients themselves and with the OMERACT requirements. ${ }^{20}$ Since 2004, OMERACT has aimed for $10 \%$ of patients with a mix of conditions (see online supplementary figure S1), geographical spread (see online supplementary figure S2) and OMERACT experience (see online supplementary figure S3).

Partner selection is still a cause for concern, particularly as regards the dual relationship between the individual patient partner and their physician. Participants reported that the current system had a number of significant advantages: this personal relationship clearly motivates patients to take part; it makes researchers feel responsible for the appropriate guidance of and funding for the partners, and precludes the selection of patient advocates. Some respondents pointed out that there might be a risk that partners might not dare to speak openly about their opinions in the presence of their own physician. In one case, a partner admitted that 'pleasing' or 'identification with' her own consultant had played a role when she felt she had to defend her consultant's point of view when delegates criticised her for not having incorporated the patient perspective sufficiently in the presented data.

As the result of structural involvement, the relationship between partners and researchers has developed into equal collaboration in many aspects of the conference. Participants have tended to raise the level of competencies required: partners are expected to speak up, provide the patient perspective, compartmentalise their clinical relationship ${ }^{9}$ and carry out tasks just like all other delegates. Most participants confirmed that partners must be able to understand the basic principles of research, contribute during discussions and receive criticism.

\section{Conference design}

OMERACT started out as an informal gathering of researchers interested in outcome measurement in rheumatology $^{33}$ and evolved into a biannual 5-day working conference with a multistakeholder approach. Participants confirmed that the modest size of the conference, the attitude of the delegates and the spirit of OMERACT as an open and inclusive initiative have all been beneficial for a positive reception of the concept of patient participation: "I think that most of the researchers and clinicians that go in here are rather open minded" (RB). Partners felt welcome at the conference: 'You do feel like you're part of the family' $(\mathrm{PH})$, and 'OMERACT is probably the most patient inclusive meeting' (PI).

The conference layout and the strong focus on active interaction and debate in small groups, including preworkshop and postworkshop meetings, have been specifically designed to serve the need to integrate diverse perspectives and to avoid one single dominant voice: "At times discussion on topics may be strongly influenced by key opinion leaders, but holding more meetings of smaller concurrent interest groups has partially remedied this problem." 34 The breakout discussions also: "support the patient contributions in what might otherwise be a very professionally oriented forum" (ibid).

Partners were officially invited to participate as full delegates with voting rights and access to all sessions, discussions and events. Some of the more experienced partners felt they were on a par with the professionals and acted as co-researchers by comoderating, reporting back or becoming coauthors (see online supplementary appendix 1). The majority of partners believed it was their role to give information or advice, but sometimes found themselves in the role of observers. New partners in particular often felt the same disparity towards professionals as is experienced in clinical practice. The interviews revealed that new researchers and research fellows sometimes also experienced this disparity.

\section{Moderation style}

The breakouts during the OMERACT conferences lie at the heart of the conference. Although moderation is part of the conference proceedings and has been described in separate guidelines (internal document), the quality of moderation was considered to be of the utmost importance: a facilitator can either help partners contribute to their full potential or relegate them to the sidelines as silent observers. The partners considered a facilitative moderation style and an environment that fosters mutual learning through open dialogue to be 
critical conditions for empowering them to make their voices heard and to contribute fully to the objectives of the sessions. One of the partners described what made her feel confident enough to say something:

Just simple things, like at the start: we had something like a semi-circle [for the seating] rather than in rows. So we could all interact and see each other. Basic stuff like that. Especially for somebody like me with a hearing disability it is important to see all the faces'. And the moderator: 'did thank everybody for coming, made us all feel welcome and stopped a couple of times through the session to say "what do the patients think?" We were all given the opportunity to speak, and weren't cut off or being manipulated or something like that, it (...) all really felt equal. (PC)

Partners were at times confronted with what seemed like a patronising attitude on the part of a moderator or other delegate. Occasional comments such as: "That is quite obvious" were felt to undermine their competences or disease experience. As a result, partners sometimes felt ignored, frustrated or unable to contribute. The language was also a barrier for some whose first language is not English. This was something that had been underestimated and partners tended to refrain from saying something when they were afraid of not using the right words or expressions.

Good moderators used the dynamics of a dialogue to articulate partners' opinions:

\section{Because one patient can say something which facts up the other patients in the room to say "yes, this is very important and I haven't thought about it but now that's been brought up: absolutely". I've seen examples of that many times at OMERACT and you almost hear the penny drop, it was all of a sudden a big light bulb goes on and everyone says 'yes, absolutely! (PH)}

Moderators' behaviour was sometimes considered unethical or to be a poor approach to sensitive issues. For example, on one occasion, a discussion on a rare rheumatic disease caused distress for one of the partners affected by that disease when mortality rates were presented. The researcher mentioned somewhat dismissively that this was not relevant to the topic under discussion. The offhand dismissal of the scientific importance of mortality in relation to the discussion topic could not easily be separated in the partner's mind from a dismissal of the importance of mortality for patients in general and for her in particular. An overview of the strategies moderators have found useful for reducing partner reported barriers is given in table 3 .

\section{Support}

According to the OMERACT organisers, the first conference that included patient involvement was actually the easiest and most successful because none of those involved had any expectations. Partners formed a homogeneous group and the programme was not demanding.
Despite the fact that support was limited and there was a minimum of organisation, patients felt welcome and accepted. ${ }^{35}$ Partners at subsequent conferences were highly motivated to learn in the OMERACT way and started to organise themselves. They formed a Patient Liaison Group responsible for communication between the patient group and the organising committee. Experienced partners developed information modules to bring newcomers up to a basic level of understanding of the scientific purpose of OMERACT. Where necessary, they approached professionals for assistance.

In 2010, partners received a preconference pack with information about the programme, lay summaries of the workshop objectives and a participant list. New partners were teamed up with a more experienced partner who took on the role of a buddy. On arrival at the conference, partners gathered together for their own dinner and an introductory meeting was held. Before the official programme started on the second day, partners also followed a half-day training session moderated by the Chair of the Liaison Group. Workshop leaders provided disease-specific patient update sessions prior to the workshops. For a better understanding of the discussion topics, important terms, questionnaires or issues were explained in more detail. Experienced OMERACT partners coordinated the production of a glossary, ${ }^{36}$ which turned out to be so useful that researchers and partners received a copy. The glossary is updated for every conference with input from the working group leaders.

The current intention of OMERACT is to optimise support by tailoring it to the individual needs and competencies of partners. To overcome the barrier of an exhausting programme, the Patient Liaison Group drew up personalised programmes that helped new partners pace themselves by making informed decisions about which sessions they should attend as a minimum, and which sessions they should attend only if their condition allowed it. Other suggestions were related to the OMERACT preconference work. It is now expected that early participation in working groups is the best way to prepare partners for taking part in the conference.

\section{Barriers}

\section{Programme intensity}

OMERACT is an overwhelming experience for all partners attending the conference for the first time. ${ }^{21}$ One significant barrier was the exhausting conference programme. The following were physically challenging: (intercontinental) travel and change of climate; accessibility of the conference venue; early and late starting times of sessions; and the duration of the conference. New partners in particular often participated far beyond their physical capacities. They were not able to decide which sessions were most relevant and consequently tried to go to all of them. The following were mentally challenging: the use of medical or methodological jargon; uncertainty about their expected role and contributions; and dealing with hierarchical power relations 
Table 3 Patient-reported barriers to collaboration and strategies to reduce these barriers

\begin{tabular}{|c|c|}
\hline Barriers to contribution identified by partners & $\begin{array}{l}\text { Helpful tools, responses and points to consider to encourage } \\
\text { partners to contribute }\end{array}$ \\
\hline $\begin{array}{l}\text { Feeling like an observer in the conference, rather } \\
\text { than a colleague } \\
\text { Not involved from the beginning } \\
\text { Lack of information } \\
\text { Not knowing what is expected } \\
\text { Feeling not prepared for the job } \\
\text { Unaware of the aims of the conference } \\
\text { Why me? }\end{array}$ & $\begin{array}{l}\text { Involve partners right from the start } \\
\text { Provide background information in understandable language } \\
\text { (research protocol) } \\
\text { Discuss mutual expectations in a face-to-face meeting before the start of } \\
\text { the conference } \\
\text { What kind of contribution is expected from the partner? } \\
\text { Does the partner have affinity with the research topic(s)? } \\
\text { Which phase or activities will the partner be involved? } \\
\text { Who takes the initiative for contact and how? } \\
\text { What are the specific needs of the partner? }\end{array}$ \\
\hline $\begin{array}{l}\text { Doubts about their added value } \\
\text { Feeling too shy to relate personal stories } \\
\text { Assumption that experiences are obvious and } \\
\text { already known to professionals } \\
\text { Low status of anecdotal knowledge }\end{array}$ & $\begin{array}{l}\text { Encourage partners deliberately } \\
\text { Adapt to a patient-centred communication style and promote open } \\
\text { dialogue, attentive listening and authentic contact } \\
\text { Invite partners to share their perspectives } \\
\text { Ask open-ended questions and probes } \\
\text { Give feedback on contributions } \\
\text { Emphasise the importance of personal experiences and provide } \\
\text { reassurance }\end{array}$ \\
\hline $\begin{array}{l}\text { Feeling unable to contribute } \\
\text { Lack of knowledge about research and } \\
\text { statistics } \\
\text { Problem with medical jargon } \\
\text { Problem with the English language } \\
\text { Hierarchy of professions } \\
\text { Power imbalance }\end{array}$ & $\begin{array}{l}\text { Tailor support to the competencies of the partners } \\
\text { Provide lay summaries } \\
\text { Create a learning environment: provide training opportunities } \\
\text { Explain jargon without being asked } \\
\text { Provide glossaries, journals and websites }\end{array}$ \\
\hline $\begin{array}{l}\text { Feeling muddled about inappropriate } \\
\text { disclosure } \\
\text { Feeling dismissed when an initiative to } \\
\text { contribute is ignored }\end{array}$ & $\begin{array}{l}\text { Partners want to be regarded as individuals, from a holistic } \\
\text { perspective } \\
\text { Try to be inclusive } \\
\text { - Respect confidentiality and apply ethical rules } \\
\text { Acknowledge contributions }\end{array}$ \\
\hline
\end{tabular}

and highly opinionated professionals. A recurring difficulty was the invisibility of the importance of one's own contribution. In sessions dedicated to their own disease, partners were more confident about their contributions than in sessions that dealt with topics they were less familiar with. The barriers experienced by new partners have been reported in detail in a previous study (ibid). Experienced partners coped better with the requirements of the conference and reported fewer barriers.

\section{Scepticism}

The notion of including patients as participants in OMERACT reached a tipping point at the final voting session at OMERACT 5 (2000). Interviewees at this conference were unanimous in their recollection of how the decision to invite patients was not impulsive but based on extensive debate among the organisers. They confirmed that it was somewhat serendipitous: although the proposal to invite patients to the next conference came spontaneously from the audience, the organisers had, in fact, discussed the issue beforehand. The majority was indifferent and did not object to the notion as an OMERACT principle.

Some respondents were not initially convinced that partners would have any added value and suggested that the leadership had extrinsic motives that is, to promote patient involvement for reasons of political correctness. Others did not believe that partners would be able to think beyond their own condition or understand the rigour of the methodological discussions. Some researchers saw the unconditional endorsement as tokenism, but did not object as long as it would have no bearing on their own research; one respondent admitted that she did not feel confident enough to express politically incorrect opinions out of fear of being disapproved by her colleagues.

After OMERACT 6, researchers gradually started to see and experience the benefits of patient involvement and changed their views. 
At the start I was not optimistic and I saw several objections. First, patients don't understand clinometric issues. Secondly, I did not see any potential contribution of patients. But I got convinced when they started to organize themselves, the glossary, the training modules... Patients proved to be good organizers to lift themselves to a higher level... Patients were professional and very motivated, which was different for other new researchers entering OMERACT and not having much interest in the methodology of outcome research. (RE)

In 2010, a few respondents still believed that the disadvantages still outweighed the benefits. They considered that the influence of partners was out of balance and feared there would be less interest in solving methodological challenges, and that there would be a negative impact on the range of topics on the research agenda. They felt compelled to engage with partners in areas of research where they barely saw any added value, such as imaging and biomarkers. Most partners confirmed this opinion and admitted that domains that are far removed from their daily life would be less likely to benefit from their input. Some partners were particularly keen to contribute to areas of research such as work, remission, flares, doctor-patient communication, adherence and non-pharmacological interventions such as selfmanagement. They believed that they could contribute to research focused on their own condition but were uncertain about providing meaningful input to other rheumatic conditions. Physicians agreed with this to a considerable extent.

\section{Patient group composition}

Institutionalisation of patient involvement gave rise to a debate on the representativeness of professionalised partners. The OMERACT policy welcomes partners to provide the 'naïve' dimension based on the assumption that what has been achieved in the past is the result of a balance between new and experienced partners (internal report; 2008). However, there has been a tendency to raise the selection criteria in order to recruit partners who are aware of the methodological issues at stake. Some respondents objected to the participation of partners who do not understand the rigour of scientific research, who tend to slow the process down and hence cause irritation during breakouts. They argued that partners should be selected in accordance with stringent criteria such as academic education and preferably a professional background in medicine or healthcare: "It makes the conversation run more smoothly." The patient perspective is important but should be obtained during preconference research work.

Other participants emphasised the irreplaceable value of new partners for generating new ideas and a 'real' patient-oriented perspective. These researchers reported the potential risks of experienced partners becoming too professional, adapting their language, identifying themselves with researchers and finally losing touch with their peers. Some respondents warned that partners who started acting as patient advocates might compromise the outcomes of OMERACT as a data-driven evidence-based conference.

\section{SUMIMARY}

Through this empirical study we now have a better understanding of the factors for successful collaboration between patients and professionals in a scientific conference. Integrating the involvement of patients as equal partners in the programme is an effective way to incorporate the patient perspective in outcome research. The way the conference is organised and the benefits as experienced by researchers have changed their perception in favour of structurally integrating partners in all parts of the conference. Factors that stimulated this process were the long-term commitment on the part of the leadership, partner selection through participating physicians and an inclusive conference design. A facilitative moderation style and the personalised support of partners were essential. Barriers were often the negativity of the facilitators, the intensity of the conference programme, scepticism among researchers and the competencies and representativeness of the patient group.

\section{DISCUSSION}

OMERACT has provided a unique opportunity to evaluate the requirement for the long-term involvement of patients as conference partners in a highly scientific environment. Our evaluation showed that structural collaboration, fostered by consensual leadership, is essential for successfully engaging with partners and confirms the finding of a case study in the field of diabetes. ${ }^{37}$ The current study has increased our knowledge and understanding of the challenges of structural involvement at an international research conference and might serve as an example for other conferences. Key opinion leaders could take a proactive lead in this. By starting to invite patients and by providing adequate training and support, scepticism and resistance to change, elsewhere identified as important barriers for implementation, ${ }^{28}$ transform into a supportive attitude. In our study, we found that scepticism is often based on prejudice surrounding the benefits and a fear of tokenism. However, the gradual engagement of partners in OMERACT has been a process of empirical learning: improving and adjusting inclusion strategies as the result of continuous reflection. Participants became much less sceptical when partners started to organise themselves and when they saw the positive influence partners had on the flow and content of the conference. Concerns that were initially expressed turned out to be unfounded: patients came with an open mind and without an agenda; they were able to transcend their own individual experiences and to understand the objectives of OMERACT. All these experiences convinced most participants that inviting 
patients is inevitable if the ongoing challenge of developing outcomes that reflect the interests of people with arthritis is to be addressed.

Although the impact of patients at OMERACT has been substantial, it is difficult to summarise how the experiential knowledge of partners is actually utilised during the OMERACT breakout sessions. Researchers are not used to taking notes about the particular contributions partners make, and journals do not expect authors to report on input given by partners. When patient involvement is an integral part of the conference, it is almost impossible to distil individual contributions. There are, moreover, hidden contributions: an impact that is not noticed either by the researcher or the partner. Finally, patients tend to underestimate the value of their own experience. More sophisticated methods are required to articulate and evaluate their experiential knowledge.

Some researchers in the field of rheumatology have, in fact, started to describe how they have involved partners, ${ }^{15} 16$ and this is necessary because patient involvement is not yet fully understood. OMERACT participants also still believe that patient expertise is not fully utilised and conditions to facilitate the contributions of partners are still far from optimal. A remaining challenge is to develop full involvement in all phases of OMERACT by engaging partners in the preconference and postconference working groups, as well as by exploring categories and phases of research where patient involvement is expected to be most beneficial. Future research will enhance our body of knowledge on the feasibility and effectiveness of different strategies to include patients in conference sessions and of our understanding of the nature and significance of lay knowledge.

Another challenge that requires further research is the representativeness of patient research partners. ${ }^{14}$ Partners have generally been educated, white, middle class and socially skilled people capable of collaborating with professionals in a critical though constructive manner. This means that important perspectives from other groups might be missed. Most professional participants believe that, despite the lack of representativeness, partners are an asset to the conference because of their personal contributions based on introspection, reflection on their own patient journey and the intense contact with other partners at several conferences. New and experienced patients make different kinds of contributions at different times, finally resulting in a kind of aggregated and synthesised expert input.

In projects that follow the dialogue method: a stepwise, multistakeholder approach for identifying priorities for health research, ${ }^{38}$ patients develop and articulate their experiential knowledge in a structured process of enclave deliberation; by exchanging and discussing personal experiences in a homogeneous group, anecdotal stories-also called 'being familiar with'-are subsequently transformed into practical knowledge ('knowing how') and expert knowledge ('knowing that'). ${ }^{19}$ All types of knowledge are important for the OMERACT conference, although there is a tendency to explore and utilise the anecdotal and practical knowledge during the preconference activities and the expert knowledge during the conference itself. Relying solely on the input of expert patients runs the risk of pseudoprofessionalism that is reported elsewhere ${ }^{39}$ : are partners empowered by their new role in research or do they lose their naivety as a patient and align easily with professionals? ${ }^{40}$ The effect may be that partners operate separately from their peers and try to ease collaboration by suppressing their experience-based knowledge. Owing to the dual relationship, partners may feel uncomfortable expressing a personal and independent voice if it contradicts the view of their own physician. It is still not known whether partners sometimes try to please their physician by avoiding disagreement.

The self-organised training and support not only empowered the individual partners, but also strengthened the mutual relationship with professionals, a process that can be described as relational empowerment. ${ }^{41}{ }^{42}$ The structural collaboration in OMERACT, fostered by regular meetings at other conferences, sensitised both parties to the importance of beliefs and priorities of the others. Partners benefited from a better understanding of the methodological challenges of outcome research, and researchers learnt about new domains that are relevant from the patient point of view. Through mutual discussion and the exchange of personal experiences, partners gained more confidence to speak up and confront researchers with their own opinions. Researchers met partners who were able to have their say without reservation and recognised partners as reliable allies. Structural involvement facilitated a mutual learning process and a better understanding of the perspectives of others. In this context, relational empowerment might contribute to a sustainable inclusion of the patient perspective in OMERACT activities without a total power reversal. ${ }^{43}$ OMERACT has created solid partnership relations, which in the longer term may result in the integration of different sources of knowledge, also known as a melting of horizons. The characteristics of this process require further exploration.

Author affiliations

${ }^{1}$ Metamedica, VU Medical Centre, Amsterdam, The Netherlands

${ }^{2}$ Department of General Practice, CAPHRI School for Public Health and Primary Care Centre, Maastricht, The Netherlands

${ }^{3}$ Patient Research Partner, Surrey, UK

${ }^{4}$ Rheumatology Unit Bristol Royal Infirmary, University of Bristol, Bristol, UK

Contributors MDW, JRK and TA conceived the idea of the study and were responsible for the design of the study. MDW carried out the document analysis and all interviews, and prepared the initial draft of the manuscript and then circulated repeatedly among all authors for critical revision. MDW and

MK-VL were responsible for the coding of the interview transcripts. All authors provided input into the phase of cross-code checking and data analysis. All authors read and approved the final version of the manuscript. 
Funding EULAR (European League Against Rheumatism) and OMERACT.

Competing interests None.

Provenance and peer review Not commissioned; externally peer reviewed.

Data sharing statement No additional data are available.

Open Access This is an Open Access article distributed in accordance with the Creative Commons Attribution Non Commercial (CC BY-NC 3.0) license, which permits others to distribute, remix, adapt, build upon this work noncommercially, and license their derivative works on different terms, provided the original work is properly cited and the use is non-commercial. See: http:// creativecommons.org/licenses/by-nc/3.0/

\section{REFERENCES}

1. O'Connell MP. Positioning impact on the surgical patient. Nurs Clin North Am 2006;41:173-92., v.

2. PatientPartner. Patient involvement in clinical research. A guide for sponsors and investigators. Soest: VSOP, 2011.

3. Facey K, Boivin A, Gracia J, et al. Patients' perspectives in health technology assessment: a route to robust evidence and fair deliberation. Int J Technol Assess Health Care 2010;26:334-40.

4. Gagnon MP, Lepage-Savary D, Gagnon J, et al. Introducing patient perspective in health technology assessment at the local level. $B M C$ Health Serv Res 2009;9:54.

5. Tritter JQ, McCallum A. The snakes and ladders of user involvement: moving beyond Arnstein. Health Policy 2006;76:156-68.

6. Abma TA, Nierse C, Widdershoven G. Patients as partners in responsive research: methodological notions for collaborations in mixed research teams. Qual Health Res 2009;19:401-15.

7. Nilsen ES, Myrhaug HT, Johansen M, et al. Methods of consumer involvement in developing healthcare policy and research, clinical practice guidelines and patient information material. Cochrane Database Syst Rev 2006;(3):CD004563.

8. De Wit M, Abma T, Koelewijn-Van Loon M, et al. Involving patient research partners has a significant impact on outcomes research: a responsive evaluation of the international OMERACT conferences. BMJ Open 2013;3:e002241. doi:10.1136/bmjopen-2012-002241

9. Hewlett S, De Wit M, Richards P, et al. Patients and professionals as research partners: challenges, practicalities, and benefits. Arthritis Rheum 2006;55:676-80.

10. de Wit MPT, Berlo SE, Aanerud GJ, et al. European League Against Rheumatism recommendations for the inclusion of patient representatives in scientific projects. Ann Rheum Dis 2011;70:722-6.

11. Abma TA. Patient participation in health research: research with and for people with spinal cord injuries. Qual Health Res 2005;15:1310-28.

12. Nierse CJ, Abma TA. Developing voice and empowerment: the first step towards a broad consultation in research agenda setting. J Intellect Disabil Res 2011;55:411-21.

13. Schipper K, Abma TA. Coping, family and mastery: top priorities for social science research by patients with chronic kidney disease. Nephrol Dial Transplant 2011;26:3189-95

14. Staniszewska S, Haywood KL, Brett J, et al. Patient and public involvement in patient-reported outcome measures: evolution not revolution. Patient 2012;5:79-87.

15. Nicklin J, Cramp F, Kirwan J, et al. Collaboration with patients in the design of patient-reported outcome measures: capturing the experience of fatigue in rheumatoid arthritis. Arthritis Care Res 2010;62:1552-8.

16. Bingham CO III, Alten R, de Wit MP. The importance of patient participation in measuring rheumatoid arthritis flares. Ann Rheum Dis 2012;71:1107-9.

17. Gossec L, Paternotte S, Aanerud GJ, et al. Finalisation and validation of the rheumatoid arthritis impact of disease score, a patient-derived composite measure of impact of rheumatoid arthritis: a EULAR initiative. Ann Rheum Dis 2011;70:935-42.

18. Nierse CJ, Schipper K, Van Zadelhoff E. Collaboration and co-ownership in research: dynamics and dialogues between patient research partners and professional researchers in a research team. Health Expect 2012;15:242-54.

19. Schipper K. Patient participation \& knowledge [thesis]. VU University, 2011.

20. OMERACT. Guiding principles for patient research partner participation in OMERACT. http://www.omeract.org/pdf/2011-0327\%20Agreed\%20Patient\%20Participation\%20Policy.pdf (accessed 18 Oct 2012).

21. de Wit MP, Koelewijn-Van Loon MS, Collins S, et al. "If I Wasn't This Robust": Patients' expectations and experiences at the Outcome Measures in Rheumatology Conference 2010. The Patient 2013. In press. doi: 10.1007/s40271-013-0017-0

22. Repping-Wuts $\mathrm{H}$. Fatigue in patients with rheumatoid arthritis (thesis). Nijmegen University, 2009.

23. Nikolaus S. Fatigue in rheumatoid arthritis: from patient experience to measurement (thesis). University of Twente, 2012.

24. Arksey $\mathrm{H}$. Expert and lay participation in the construction of medical knowledge. Sociol Health IIIn 1994;16:448-68.

25. Popay J, Williams G. Public health research and lay knowledge. Soc Sci Med 1996;42:759-68.

26. Schipper K, Abma TA, Van Zadelhoff E, et al. What does it mean to be a patient research partner? An ethnodrama. Qual Inq 2010;16:10.

27. Caron-Flinterman JF, Broerse JE, Bunders JF. The experiential knowledge of patients: a new resource for biomedical research? Soc Sci Med 2005;60:2575-84.

28. Jinks C, Ong BN, O'Neill TJ. The Keele community knee pain forum: action research to engage with stakeholders about the prevention of knee pain and disability. BMC Musculoskelet Disord 2009;10:85.

29. Elberse JE, Caron-Flinterman JF, Broerse JE. Patient-expert partnerships in research: how to stimulate inclusion of patient perspectives. Health Expect 2011;14:225-39.

30. Stake RE. Standards-based and responsive evaluations. Thousand Oaks: Sage Publications, 2004

31. Boers M, Strand V, Simon L, et al. OMERACT 8-8th International consensus conference on outcome measures in rheumatology clinical trials. J Rheumatol 2007;34:599.

32. Kirwan J, Heiberg T, Hewlett $S$, et al. Outcomes from the patient perspective workshop at OMERACT 6. J Rheumatol 2003;30:868-72.

33. Boers $M$, Brooks $P$, Strand CV et al. The OMERACT filter for outcome measures in rheumatology. J Rheumatol 1998;25:198-9.

34. Saag KG. OMERACT 6 brings new perspectives to rheumatology measurement research. J Rheumatol 2003;30:639-41.

35. Quest E, Aanerud GJ, Kaarud S, et al. Patients' perspective. $J$ Rheumatol 2003;30:884-5.

36. Richards P, De Wit MPT. OMERACT Glossary. http://www.omeract. org/pdf/OMERACT11\%20Glossary.pdf (accessed 20 Oct 2012).

37. Lindenmeyer A, Hearnshaw $\mathrm{H}$, Sturt J. Assessment of the benefits of user involvement in health research from the Warwick Diabetes Care Research User Group: a qualitative case study. Health Expect 2007;10:268-77.

38. Abma TA, Broerse J. Patient participation as dialogue: setting research agendas. Health Expect 2010;13:160-73.

39. Van De Bovenkamp HM. The limits of patient power. Examining active citizenship in Dutch health care. Dissertation. Erasmus University, 2010.

40. Abma TA, Molewijk B, Widdershoven G. Good care in ongoing dialogue. Improving the quality of care through moral deliberation and responsive evaluation. Health Care Anal 2009;17:217-35.

41. Plaat MVD. Locating the feminist scholar: relational empowerment and social activism. Qual Health Res 1999;9:773-85.

42. Baur VE, Abma TA, Widdershoven GA. Participation of marginalized groups in evaluation: mission impossible? Eval Program Plann 2010;33:238-45.

43. Cornwall A, Jewkes R. What is participatory research? Soc Sci Med 1995;41:1667-76. 